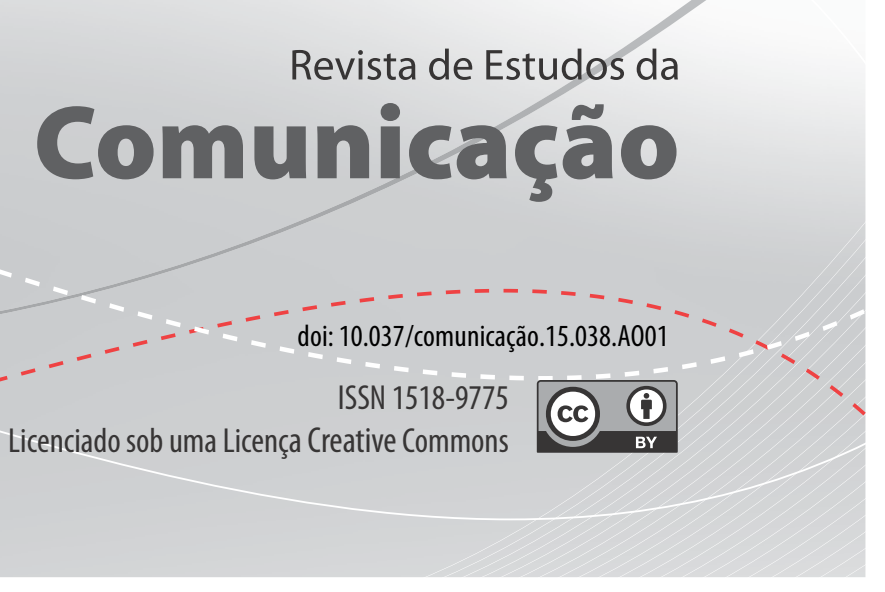

\title{
El flow se estanca: el contramodelo 'televisivo' de Netflix
}

\author{
The flow stops: the Netflix TV countermodel
}

\author{
Jaime Costas Nicolás
}

Especialista da Universitat Pompeu Fabra, Barcelona, Espanha, e-mail: aimejcn@hotmail.com

\section{Resumen}

El medio digital, concretamente la plataforma Netflix, ofrece un nuevo set de herramientas listo para revolucionar las ficciones seriales. En este nuevo contexto, el espectador adquiere el total control sobre el modo de consumir sus series favoritas, el cuándo, dónde y cuántos. Siete años después de ser cancelada, Arrested Development es resucitada para una cuarta temporada dentro de este ecosistema digital. Consciente de las posibilidades del medio, esta sitcom adopta una estructura serial inédita en la que los espectadores, debem interac- 
tuar con las imágenes con el fin de reconstruir el relato: nace el espectador activo dentro de una serialidad que denominase ergódica.

Palabras clave: Ergódico. Serialidad digital. Arrested Development. Comedia. Televisión. Estructuras.

\section{Abstract}

The digital medium, especially in the case of Netflix, offers a new set of tools ready to revolutionize the world of serial fiction. In this new context, the audience acquires total control over the consumption habits of TV shows: when, where and how many. After being canceled for seven years, Arrested Development is brought back to life within this digital ecosystem. Aware of the possibilities of the medium, this sitcom displays a unique serial structure in which we, the audience, need to interact with the images in order to reconstruct the story: the active viewer is born within a new type of seriality we will refer to as ergodic.

Keywords: Ergodic. Digital seriality. Arrested Development. Comedy. Television. Structures.

"You can't take a picture of this, it's already gone."

Nate Fisher

Con esta última línea de diálogo se cerraba la gran Six Feet Under (HBO, 2001-2005). Recordemos el momento: en el último episodio de la serie, 'Everyone's Waiting' (5x12), Claire Fisher (Lauren Ambrose), hija pequeña de esta familia dueña de una funeraria, decide emanciparse y dejar atrás toda una vida para mudarse a Nueva York, con la intención de perseguir sus metas artísticas. En el día de la despedida decide sacar una fotografía de todos ellos y en ese instante su difunto hermano, Nate (Peter Krause), le susurra al oído que ese momento ya ha pasado, que no se puede inmortalizar. A través de este mecanismo, propio de la serie, de desarrollar el monólogo interior de un personaje mediante otros personajes ya fallecidos, Allan Ball, guionista y creador de la ficción, hace un comentario final en su personal oda a la vida (y a la muerte). Nuestra existencia no es más que una sucesión de breves instantes irrepetibles, imposibles de captar a través de la cámara fotográfica debido a las reglas temporales bajos las cuales nos regimos, lineal, constante y siempre hacia delante. La vida es pues, como nos muestra el famoso epílogo con el que se cierra la serie ${ }^{1}$, una suma constante de momentos

En él vemos los acontecimientos más destacados del futuro de los personajes fuera de la cronología de la serie: bodas, logros laborales, nacimientos, cumpleaños, y, una a una, la muerte de cada uno de ellos. 
efímeros que pasan ante nuestros ojos, y a los que no podemos echar la vista atrás... hasta alcanzar el instante final, el más efímero de todos ellos, la muerte.

Existe otra posible interpretación de esta frase con la que se cierra la serie: las cadenas de televisión, compuestas por ficciones, telediarios, magazines o, sobre todo, publicidad, crean una continua concatenación de instantes en los que no podemos pararnos porque inmediatamente son sustituidos por el siguiente programa de la parrilla. Los seriales televisivos representan, dentro de estas ataduras de las networks, el arte de lo efímero. Un arte atrapado dentro de un modelo cargado de tiempo dentro de sus hábitos de consumo, en el que no podemos pararnos ni un instante, el momento ya ha pasado. El espectador debe estar a una hora concreta en un lugar concreto, delante del televisor, para no perderse su serie favorita. Además, debe repetir este ritual durante un número de semanas para no perderse ningún capítulo en toda la temporada. Este modelo impedía realizar comprobaciones factuales, en el sentido de volver hacía atrás, como por ejemplo en las novelas, para comprobar algún hecho concreto, evitando también una reinterpretación de hechos pasados a partir de la luz vertida sobre ellos a través de acontecimientos posteriores (HAYWARD, 1997, p. 135). Todo este modelo, este fenómeno, es lo que Raymond Williams denomina la teoría del flow ${ }^{2}$.

Un flujo constante de contenidos que se ha vuelto casi intrínseco al medio televisivo y que nos hará cuestionarnos si los modelos de distribución alternativos, que veremos con Netflix, pueden seguir siendo considerados televisión y sus ficciones como televisivas. Tan ligado está el flow a la televisión que las ficciones seriales han aprendido a interaccionar con él. Por ejemplo, en las cadenas en abierto en las que nos encontramos pausas publicitarias incrustadas dentro de los episodios, las series han aprendido a introducir "staged climatic moments" (SODANO, 2012, p. 28), una especie de 'pequeños cliffhangers', antes de cada corte con el fin de que la audiencia se quede clavada en sus asientos, expectante. Sin embargo, el ejemplo más claro de la normalización de este fenómeno ocurre en la serie 24 (FOX, 2001). Es por todos conocido el dispositivo temporal de la serie la cual ocurre en tiempo real, simultáneo al de la audiencia, es decir, una hora por episodio conformando un día completo por temporada. La serie se encarga de recordarnos esta cuenta atrás mostrando explícitamente en nuestras pantallas un temporizador que va marcando la hora en la que se encuentra el inmortal Jack Bauer (Kiefer Sutherland). Lo más curioso es que, como sabemos, las series en abierto no duran exactamente una hora sino cuarenta minutos, dejando así espacio para las pausas publicitarias. 24 es tan consciente del modelo en el que está inscrito que crea una elipsis en su narración especialmente diseñada para estos instantes, a la vez que el reloj avanza unos minutos. "Les pauses per als anuncis semblen actuar, només a nivell cronològic,

Término acuñado por Williams en Television: Technology and Cultural Form. 
com si fossin un més d'aquests microfragments que es van succeint en el relat" (JIMÉNEZ, 2010, p.115), es decir, la estructura del relato se amolda al contexto del flow. Un formato conformado por una corriente temporal que avanza incesablemente y que arrastra con ella al tiempo serial.

Lo cierto es que este modelo puede tener los días contados. El cauce de las cadenas parece secarse poco a poco, con audiencias más y más fragmentadas entre los diversos medios, y la network era junto a su diseño de industria están fuertemente amenazados ${ }^{3}$.

\section{Nuevas formas de ver la 'televisión' en la post-network era}

Actualmente nos encontramos en lo que Amanda Lotz denomina la postnetwork era en la que gracias a los avances tecnológicos podemos ver "whatever show you want, whenever you want, on whatever screen you want" $(2007$, p. 108) y que, por tanto, se caracteriza por la pérdida de poder de las cadenas en detrimento de la audiencia, que ahora toma el control de la programación y atraviesa 'océanos de tiempo' a su antojo. El espectador ya no tiene que seguir las rígidas reglas de la parrilla televisiva sino que puede tomar sus propias decisiones en cuanto a rituales de consumo. No sólo 'ver la televisión' ha dejado de significar sintonizar ciertas cadenas, además, con el origen, por ejemplo, de las plataformas digitales, incluso el aparato televisivo ha dejado de ser parte de la ecuación. Ahora podemos hacer streaming o descargar por torrent nuestros programas favoritos a cualquiera de nuestros dispositivos, ya sea el teléfono, el ordenador o la tablet. La televisión, esa pequeña cárcel para la ficción rectangular, en mi caso personal, ha dejado de existir para dar paso a nuevos canales de distribución adaptables a la disponibilidad de cada individuo. Entre estos nuevos canales:

Television adopted multiple possible revenue streams in ways that mirror the bookstore (DVD sell-through, iTunes downloading), magazine subscription (premium cable networks such as $\mathrm{HBO}$ ), and the library (free on demand), as well as other related venues, such as the subscription library model of Netflix. (...) Each of these possible transactions of capital for content created new and distinct relationships between the economic model, programming, and how these form of television might function as a cultural institution (LOTZ, 2007, p. 761).

Múltiples artículos se han escrito en el último año sobre la lenta pero constante perdida de audiencia por parte, sobre todo, de las cuatro grandes cadenas en abierto (FOX, $A B C, N B C, C B S$ ). Un par de artículos dónde podemos consultar datos concretos son disponibles en: <http://pando.com/2014/05/12/the-biggest-threat-to-the-tv-advertising-market-is-simply-how-muchtv-there-is-now/> y<http://www.businessinsider.com/cord-cutters-and-the-death-of-tv-2013-11>. 
Los primeros dispositivos que cambiaron las reglas, aquellos de almacenamiento, ya sean DVDs, VHSs, o DVRs, fueron también el origen de uno de los precedentes de los mind-game films. Elsaesser habla en este artículo de "DVD-enabled movies" las cuales combinan la interactividad del videojuego, a través de los menús donde seleccionamos los contenidos que queramos, y las posibilidades de relectura del libro, pudiendo parar la película o ir hacia delante y atrás, de forma similar a la experiencia que más tarde nos encontraríamos con las series en Netflix. Otro modelo del que habla Lotz, el de los canales premium, también supuso un punto de unión entre la network y la postnetwork era. Su modelo sin publicidad (sin interrupciones en la unidad ficcional del episodio dentro del flow) apuesta por dar más libertad creativa a los showrunners, respecto al contenido de la serie y al número de episodios en los que dividir cada temporada. Además, su plataforma de streaming lanzada en 2010, HBO Go, ofrece todos sus contenidos online, con todo lo que eso conlleva, aunque con un modelo de distribución propio del flow, haciendo disponible cada semana el capítulo que se ha emitido por televisión. Es por ello que esta plataforma supone una bisagra entre los dos modelos, network y plataforma digital. A su vez, es sintomático que uno de los directivos de Netflix, Ted Sarandos, declarará que "The goal is to become HBO faster than HBO can become us." (HASS, 2013), la compañía tiene como objetivo adoptar el famoso 'modelo HBO' con contenidos de alta calidad y un amplio reconocimiento por parte de crítica y público antes de que la propia HBO realice su transición al medio digital en el que posiblemente se decidirá el futuro de la ficción serializada.

Finalmente, tenemos el entorno online, y no sólo debemos de pensar en Netflix si no en Amazon ${ }^{4}$, Youtube o cualquier otra plataforma de vídeos, e incluso en apps como Vine o Instagram ${ }^{5} y$, por supuesto, los torrents (no podemos obviar la herramienta más popular de consumo de ficción serial americana fuera de EEUU). Son todas estas 'posibilidades' las que han vaciado el aparato televisivo, como ya comentábamos, para convertirla en simplemente una pantalla mediante la cual

\footnotetext{
Que en su carrera para lanzar contenidos propios ha reinventado la 'batalla de episodios piloto' que se produce en cada cadena por ver qué series serán finalmente producidas. En Amazon, en vez de dejar estas decisiones en manos de los directivos, decidieron poner los pilotos a disposición de todos los usuarios, para ser los más populares los que finalmente serían elegidos para continuar su historia.

En el caso de Instagram tenemos un uso paradigmático de que utilizar una app de este tipo para 'emitir' una ficción y que tenga sentido. En el episodio 1x08 de la sitcom animada Rick and Morty, 'Rixty Minutes', creada por Dan Harmon, sus protagonistas se dedicaban todo el episodio a hacer zapping por todos los canales del universo, mostrándonos un poco de cada uno. Dada esta estructura altamente fragmentada y aleatoria el episodio se hizo disponible el día anterior de su emisión a través de Instagram. El porqué de la elección de esta app es el siguiente: Instagram sólo soporta vídeos con una duración máxima de 15 segundos por lo que se tuvieron que subir un total de 109 para completar el episodio y, al mismo tiempo, esta técnica mimetizaba el leitmotif fragmentario del capítulo.
} 
interactuar con DVDs, Internet o videojuegos (LOTZ, 2007, p. 654). Las cadenas de televisión desaparecen, el flow se seca finalmente y lo que quedan son carreteras mediante las cuales el espectador puede viajar libremente y apearse, o reiniciar el trayecto, en cualquier momento. Esa librería de la que Lotz hablaba está ya llena de libros, libros que, sin embargo, en su mayoría no han nacido en el medio digital sino en el televisivo y, por lo tanto, su estructura ha sido construida alrededor del modelo funcional de los canales de televisión. Consecuentemente, los nuevos hábitos de visionado que esta revolución tecnológica permite (la libertad del cuándo, cuántos y cuántas veces) pueden no ser los adecuados para las ficciones pensadas para ser vistas semanalmente. Es en la plataforma Netflix donde podemos experimentar con todo tipo de series, tanto aquellas que han sido emitidas en cadenas de televisión y que posteriormente Netflix ha comprado los derechos de distribución, como aquellas que la propia empresa ha creado dentro de su programación original para atraer usuarios (no olvidemos que lo serial nació a finales del siglo XIX como una forma de asentar una base de consumidores ante una nueva industria cultural, en aquel momento la literatura de masas).

Primero fueron los DVDs, más adelante la HBO y, finalmente, lo digital, todos ellos supusieron una misma consecuencia para el espectador: "viewing is no longer linear" (LAVANDER-SMITH, 2012, p. 60). Ver una serie ya no suponía tener que efectuar ese rito semanal de sentarse en el salón frente al aparato, el viewser ${ }^{6}$ podía verse ahora toda una temporada en una tarde de forma maratoniana, en lo que se conoce como el binge watching ${ }^{7}$. Esta forma de consumo surge de forma sintomática en la sociedad hiperconsumista ${ }^{8}$ del siglo XXI (la del más, más y más, un episodio más) y es el claro contrapunto del visionado fragmentado que se proponía en la era pre-digital.

Nos encontramos ante dos modelos de consumo serial. Por un lado tenemos el fragmentado, aquel orquestado y dominado por las cadenas de televisión para que el mayor número de personas posible lo vean al mismo tiempo. Este sistema funciona claramente a favor de la industria televisiva, tenemos un producto que se alarga durante meses y que obliga a los espectadores a verlo en simultaneidad, con los beneficios económicos que eso aporta en publicidad. Es para este tipo de consumo que el $99 \%$ de ficciones americanas han sido adaptadas. Pensemos en un mecanismo como el cliffhanger: a través de este recurso narrativo den-

\footnotetext{
Término que adopta Paul Booth para definir al espectador digital que surge de la mezcla de viewer (espectador) y user (usuario). (2012, p. 192)

Literalmente: darse un atracón de visionados.

Definida por Lipovetsky dentro de su hipermodernidad: "Desde hace mucho tiempo la sociedad de consumo se anuncia bajo el signo del exceso (...) Cada dominio tiene un aspecto en cierto modo exagerado, desmesurado, extralimitado. (...) La escala paroxística del "siempre más» se ha introducido en todos los ámbitos del conjunto colectivo." (2006, p. 58)
} 
tro de la distribución semanal, los televidentes son dejados huérfanos durante días (o meses en el caso de finales de temporadas) "to imagine in that gap what happens next" (SODANO, 2012, p. 33). Una serie paradigmática que supo utilizar este elemento a su favor fue Lost (ABC, 2004-2011). Mediante los finales de cada episodio, en los que la serie se proponía desencajar la mandíbula del espectador, Lost creaba una ansiedad extrema en sus seguidores cuyo único consuelo era el de acudir a Internet a leer, escribir, teorizar y estudiar la serie para lograr descubrir qué iba a pasar a continuación. Podríamos decir que Lost se convirtió en el fenómeno global y cultural de masas que fue en su momento no por esos 40 minutos semanales, sino por los 7 días entre cada uno de los episodios en los que el fandom engrandecía el mito de aquella isla que se encontraba en el flow televisivo. Otras ficciones que también supieron adaptarse dentro de este paradigma fueron In Treatment y 24, mediante el uso de un tiempo diegético en directa relación con el tiempo del espectador: el lunes la audiencia ve al paciente que va a la consulta de Paul Weston los lunes, mientras que la hora que pasamos viendo las aventuras de Jack Bauer es el mismo tiempo que pasa para él en uno de esos "peores días de su vida".

En el grupo que conforman las "convenience technologies" y que otorga el poder de decisión al viewser surge el modelo contrapuntístico de consumo serial, el modelo maratoniano, mediante el cual nosotros controlamos prácticamente todas las variables que se nos imponían en el flow, la hora de emisión, el televisor como aparato único de distribución, y la cantidad de episodios y su orden (aunque casi todas las series promulgen la consecutividad episódica). Ver una serie de esta forma "highlight(s) the values of unity, complexity, and clear beginnings and endings, qualities that are hard to discern through the incremental releases of seriality" a la vez que "make(s) one more conscious of the season as a narrative unit (...) and without commercials or interruptions, helps emphasize the medium's artistic merits over commercial imperatives" (SODANO, 2012, p. 37). Características que se aprecian, sobre todo, en series que siguen un modelo más próximo al serial ${ }^{9}$. Pensemos, por ejemplo, en series de cable como Breaking Bad o The Wire, en las que la fragmentación narrativa que exige el episodio se asemeja más a una imposición del medio que a un mecanismo que enriquezca estas grandes novelas americanas.

Pero también tenemos series en las que se perdería parte de la experiencia. Si consumiésemos Lost de esta forma nos habríamos perdido ese factor social, el 'water-cooler talk', que se originaba alrededor de la serie entre cada episodio ${ }^{10}$, dado que tendríamos que esperar a que la temporada hubiese terminado para poder hacer nuestra maratón particular y anularíamos también esos tiempos muertos entre episodios en los que el fandom lanzaba todas sus teorías. A pesar de

Entendiendo por serial como aquella estructura en la que las tramas de la serie se extienden más allá de la unidad del episodio.

10 Ahora trasladado a las redes sociales y a los blogs. 
ello, Lost sigue siendo una buena ficción con la que hacer maratones de episodios dado el alto grado de adicción que ésta producía. No obstante, existen también series de televisión que dada su estructura no sólo no ganan en cohesión con el binge watching sino que darse un atracón de ellas puede resaltar sus costuras. Estoy pensando en series con episodios autconclusivos, cerrados, como la saga CSI o Law \& Order, en las que su estructura tremendamente repetitiva (crimen, investigación, resolución del caso) no ofrece un motivo al espectador lo suficientemente convincente como para ver 5 episodios seguidos de una sentada. Todo lo contrario, cuántos más seguido la veamos, más saldrá a relucir el esqueleto que sustenta cada uno de los episodios y más probable es que nos acabe aburriendo siempre más de lo mismo.

En resumidas cuentas, tenemos dos maneras diferentes de entender el consumo serial que benefician o perjudican narrativamente a depende qué modelos de serialidad televisiva. Sin embargo, todas las series que hemos utilizado para ejemplificar los pros y contras del flow y del binge han nacido y han sido emitidas dentro del primer formato, y todas ellas han sido estructuradas y construidas alrededor de esta forma de entender la televisión. Incluso series que han sido creadas en medios digitales, como es el caso de House of Cards (Netflix, 2013-) o Orange Is the New Black (Netflix, 2013-), tampoco se adaptaron al contexto digital y siguieron costumbres propias del flujo televisivo, con relatos cronológicamente lineales, reflejados en la consecutividad episódica.

\section{Una serialidad propia del medio digital}

A día de hoy, existe sólo una excepción a todo esto, Arrested Development (FOX, 2003-2006, Neftlix, 2013), una sitcom llamada a revolucionar la serialidad. La comedia retrata las 'desgracias' de una familia de clase alta de California, los Bluth, en plena crisis tras el arresto de su patriarca, envuelto en un caso de corrupción urbanística (un punto de partida muy made in Spain). El hijo mayor, Michael, se hará entonces con el mando de la empresa constructora familiar e intentará mantener a la familia unida durante esta época difícil. Por supuesto, como es regla dentro de este género, pero especialmente en este caso, el hilo narrativo no es más que una mera excusa para poner en escena a un grupo de personajes altamente disfuncionales y eternamente encasillados dentro de sus defectos. Esta comedia fue emitida durante tres años en la cadena FOX y posteriormente cancelada debido a su baja audiencia. Siete años más tarde, sin embargo, la plataforma Netflix la rescató para producir una nueva temporada.

Veamos cómo la resurrección de este proyecto se llevó a cabo: en el año 2012 la cuarta temporada de Arrested Development entraba en fase de produc- 
ción. En principio, Hurwitz había ideado esta nueva etapa como una película para poner broche final a las historias de sus personajes. Sin embargo, pronto se dio cuenta de la imposibilidad de comprimir las historias individuales de cada uno de sus personajes en una sola unidad (GREENE, 2013) y es que, tras seis años de hiatus, los actores que interpretaban a la familia Bluth tenían otros compromisos laborales y le fue prácticamente imposible escribir una trama coral, con varios miembros del cast en pantalla, como en las primeras temporadas. Por lo tanto, cada personaje tendría su trama individual en la que se irían cruzando con los otros familiares puntualmente (aunque la temporada también cuente con dos escenas en concreto con todos los miembros del cast original presentes). Que todo esto ocurriera en plena fase de producción hizo que lo que luego ocuparía distintos episodios se estuviese rodando al mismo tiempo y es que, debido al uso de una estructura trama-personaje ${ }^{11}$ donde cada episodio se centraba únicamente en un miembro de los Bluth, se decidió no cortar los episodios cronológicamente, como sería lo habitual, si no que en cada episodio se contenían la mayoría de las escenas de su protagonista, en una suerte de serie antológica con los 15 episodios ocurriendo simultáneamente ${ }^{12}$. Por lo que situaciones dónde veíamos a dos o más personajes se editaban de forma fragmentada entre dos o más episodios. La mayoría de gags, tramas, y planos, quedan incompletos en cada uno de sus 15 episodios, prácticamente imposibles de cerrar para el espectador medio si sólo tuviese la posibilidad de ver un episodio, una vez, cada semana y sin la posibilidad de pararlo o rebobinar hacia atrás para rever ese momento que no ha comprendido del todo.

La serie en su cuarta temporada en Netflix fue consciente del nuevo contexto digital en el que estaba inscrita y supo aprovecharlo para crear un nuevo tipo de serialidad adaptada al nuevo modelo de consumo que este medio propone. Es lo que denomino una serialidad ergódica ${ }^{13}$, heredera de obras literarias como Finnegans Wake (James Joyce, 1939) o House of Leaves (Mark Z. Danielwski, 1999) en las que el lector debía realizar un esfuerzo extra, ya sea la relectura de la obra que

\footnotetext{
Una vez más surge la comparación inevitable con Lost en la que en cada episodio veíamos la background story de un personaje diferente e incluso en algunos casos, como en el infame episodio de Nikki y Paulo, 'Expose', eventos que ya habíamos visto en anteriores episodios eran revisitados desde un nuevo punto de vista.

12 En palabras de Hurwitz: "We ended up with an eight-hour movie of Arrested Development where the pieces do kind of come together. Not only was the show told out of sequence, it was shot out of sequence." (GREENE, 2013). También, en otra entrevista a Kabir Akhtar, montador principal de la temporada: "None of the episodes were completely shot until they all were. So, while on most shows you finish one episode before starting on the next, here we were working on many of them at once." (BRENNER, 2013)

13 Del griego ergon (trabajo) y hodos (camino), es aquel tipo de forma artística en la que el lector/espectador debe realizar un esfuerzo físico, más allá de lo trivial, para atravesar la obra (AARSETH, 1997, p. 136).
} 
propone Finnegans con un final cuya frase enlaza con la primera del libro, o con la mezcla de idiomas con la que está escrito el libro, o a través de la elección del orden de lectura en las páginas con múltiples textos inconexos en House of Leaves, para comprender la totalidad de la obra. Nuestra sitcom sólo puede ser entendida con las posibilidades de control que ofrece Netflix.

Pasemos ahora a un ejemplo concreto: en el episodio centrado en George Michael (Michael Cera), 'It Gets Better', descubrimos que durante sus años universitarios estuvo de intercambio en España, donde trabaja de au pair para una familia. Un día, la madre de esta familia se insinúa, por decirlo de forma eufemística, al personaje de Michael Cera mientras le dice "The drones are coming. Nothing matters now", para posteriormente besarlo. No se vuelve a hacer referencia a este posible ataque en toda la trama en España o en todo el episodio, y la palabra drone ni siquiera se vuelve a pronunciar. Vayamos ahora al capítulo que gira alrededor de Buster (Tony Hale), 'Off the Hook'. En su trama episódica, tras el arresto de su madre, el personaje se encuentra sin rumbo fijo y decide volver a alistarse en el ejército. Debido a su discapacidad física (y a su afición a los videojuegos) a Buster se le asigna el puesto de piloto de drones. Tras pasar demasiadas horas de vuelo comete un error y lanza un misil contra un museo en Madrid al mismo tiempo que se da cuenta de que la simulación no era en realidad un videojuego.

Obviamente, explicarlo es como diseccionar la rana y en seguida vemos la conexión entre ambos momentos. Sin embargo, si pensamos en la distancia que los separa, tanto temporal como físicamente dentro de la diégesis, y el ritmo acelerado y denso en cuanto a gags habitual de la ficción, la conexión entre ambas situaciones es, cuanto menos, oscura. El fan tiene que ver los episodios en múltiples ocasiones ${ }^{14}$ hasta que cada momento, por muy efímero que sea, forme parte de su imaginario, sea aprendido, y pueda aplicarlo cuándo ese momento sea reactivado a partir de otro instante, por muy alejado que esté. Hemos pasado de ser Jeff (James Stewart) en Rear Window (Alfred Hitchcock, 1954) voyeurístico y pasivo, simplemente observando y zapeando entre ventanas, a convertirnos en un espectador que toca e interactúa con las imágenes como Max Renn (James Woods) en Videodrome (David Cronenberg, 1983).

Ese modelo cargado de temporalidad que era el flow no tiene cabida en un modelo que busca lo simultáneo y lo instantáneo, tanto en la trama de sus personajes -todos los episodios ocurren simultáneamente- como en los hábitos de consumo de sus fans. Cada episodio es en sí autoconclusivo, dado que se entra en el arco narrativo de un sólo personaje, pero a través de esta nueva serialidad ergódica somos nosotros los que tenemos que encontrar unas conexiones ocultas entre

En mi propia experiencia la conexión surgió tras el cuarto visionado de la temporada para realizar este ensayo. 
episodios a través de las pistas que nos ofrece la ficción para, de este modo, encajar todos las piezas del puzzle dentro de un todo.

La integración de Arrested Development dentro de esta plataforma de video on demand es equivalente a la que las series de televisión habían desarrollado a lo largo de los años dentro del flow, e incluso han sabido adaptarlo a modo de gag dentro de la narración. En el episodio 14, 'Off the Hook', centrado en el edípico Buster, después de que su madre Lucille haya sido encarcelada, acude a casa de su vecina, Lucille Austero, aka Lucille 2, para que lo acoja. Cuándo ésta le pregunta si de verdad ha superado su relación con su madre y está preparado para vivir con ella, el narrador nos dice "Buster thought he was, although there was one ominous sign.", y a continuación Buster responde "I am ready for that, Lucille", en vez de utilizar su apodo real, Lucille 2. Finalmente, el narrador nos matiza "Before you accidentally skip back too far and wind up in the middle of the Maeby episode, trust me, no 2 was spoken.". Con este simple (meta)gag, Ron Howard reconoce las posibilidades de control que ofrece Netflix desde dentro de la propia narración, además de dar una pequeña pista de cómo mucho de sus gags tienen que ser casi estudiados por parte de los activos usuarios.

Más allá de este ejemplo puntual, en cada una de las tramas-personaje (cada episodio sigue la historia de uno de ellos), dado que su inicio es siempre in media res, llega un momento en el que se realiza un flashback para trasladarnos al inicio de la historia. Este recurso narrativo es llevado a cabo a través de una cortinilla en el que vemos una barra de reproducción inferior con las palabras "then" y "now" rebobinando hacia atrás, mientras un mosaico de imágenes que veremos más adelante en el episodio aparecen en la pantalla. Esta máscara no hace más que reflejar el reproductor de vídeo de la propia Netflix que aparece en las pantallas cuando manipulamos el episodio, ya sea para pararlo o para desplazarnos hacia delante o atrás, lo que nos lleva a la siguiente conclusión: la cuarta temporada de Arrested Development no sólo nace del vientre digital de Netflix sino que la propia plataforma forma parte del (hiper)texto de la ficción ${ }^{15}$. Es a través de su interfaz que podemos elegir entre estos 15 textos para elegir nuestra propia historia, no es casualidad que el motivo visual con el que se promocionó esta temporada fuera el de los containers que se apilan en los puertos, conteniendo cada uno un personaje para formar un todo.

Esta misma relación simbiótica entre narración, estructura y formato físico es análoga a la que nos encontrábamos en la literatura ergódica en Finnegans Wake, en el que la última frase se conectaba con la primera, o con la multiplicidad

\footnotetext{
De hecho, entre el catálogo de Netflix podemos encontrar películas y programas ficticios que aparecen dentro de la sitcom como son el reality sobre escándalos en el que sale la propia familia Bluth, Scandalmakers, o el film que reflejaba el amor prohibido entre Maeby (Alia Shawkat) y George Michael, Les Cousins Dangereux.
} 
textual que el laberinto de House of Leaves presentaba por página. De la misma forma que este tipo de literatura supuso una pequeña revolución en el formato libro, y que teóricamente desembarcaría en el hipertexto digital, Netflix, y otras plataformas similares, suponen una revolución drástica de la creación y consumo televisivo a todos los niveles, creando un nuevo paradigma industrial.

Netflix recoge en una base de datos toda la información referente a los hábitos de consumo de sus usuarios y a partir de ella predice qué series originales tendrían éxito entre sus espectadores. Unos espectadores que pagan una cuota mensual por tener el control de sus pantallas, hasta tal punto que ya no sólo eligen qué ver, si no que en este sistema de oferta/demanda digital deciden, de forma indirecta, qué contenidos se van a crear para él. En esta maquinaria, paralelamente ergódica en el sentido de que es el propio usuario el que decide qué historias se crean, sin margen de error, Arrested Development surge como el paradigma de lo que se puede hacer con una nueva caja de herramientas, una serie hecha para los fans y, al mismo tiempo, por los fans.

Hace más de 20 años, Robert Coover hablaba de forma irónica del fin de los libros en favor de "a geographical landscape or exitless maze, with beginning, middles and ends being no longer part of the immediate display" y en los que "there are no hierarchies (...) conventional text divisions are replaced by evenly empowered and equally ephemeral window-sized blocks of text and graphics" (1992). Es sorprendente cómo podríamos aplicar casi palabra por palabra ${ }^{16}$ su descripción de los orígenes del hipertexto a estos orígenes del serial digital y ergódico. Los dos supusieron una reformulación del soporte físico representativo de su arte y cambiaron nuestra forma de leer y de ver. El primero posiblemente no haya triunfado entre las masas y haya sido relegado al campo de la literatura más experimental, el segundo... sólo el tiempo lo dirá. Una cosa es segura, seremos nosotros, los espectadores, en este modelo de oferta y demanda de contenidos, los que decidamos.

\section{Referencias}

AARSETH, E. J. Cybertext: Perspectives on Ergodic Literature. Londres: The John Hopkins University Press, 1997.

BRENNER, L. "How Arrested Development editor Kabir Akhtar solved the 'Season 4' puzzle (Q\&A)". Entrevista con Kabir Akhtar. Southern California Public Radio. 24 de Mayo, 2013.

En vez de "window-sized blocks of text" hablaríamos de "windows-sized images". 
COOVER, R. "The End of Books". The New York Times on the Web. The New York Times. 21 de Junio, 1992.

GREENE, A. "Arrested Development Creator Mitch Hurwitz on His Two-Year Odyssey To Revive the Show". Entrevista con Mitchell Hurwitz. Rolling Stone Magazine. Rolling Stone. 20 de Mayo, 2013.

HASS, N. "And the Award for the Next HBO Goes to...". GQ Magazine. Condé Nast. Febrero. 2013.

HAYWARD, J. Consuming Pleasures: Active Audiences and Serial Fictions from Dickens to Soap Opera. Lexington: The University Press of Kentucky, 1997.

JIMÉNEZ MORALES, M. Finals sense fi. Estudi de la construcció serial a 24, Prison Break $i$ Heroes. Tesis doctoral. 2010. Barcelona: Universitat Pompeu Fabra.

LAVANDER-SMITH, J. “IT'S NOT UNKNOWN". The Loose- and Dead-End Afterlives of Battlestar Galactica and Lost". En Time in Television Narrative: Exploring Temporality in Twenty-First-Century Programming. Ed. Melissa Ames. Jackson: University Press of Mississipi. 2012, p. 56-67.

LIPOVETSKY, G. Los Tiempos Hipermodernos. Barcelona: Anagrama, 2006.

LOTZ, A. The Television Will Be Revolutionized. Nueva York y Londres: New York University Press. Kindle, 2007.

SODANO, T. M. The Industry Changes and Technological Advancements That Paved the Way to "New" Television Ventures. En Time in Television Narrative: Exploring Temporality in Twenty-First-Century Programming. Ed. Melissa Ames. Jackson: University Press of Mississipi. 2012, p. 27-41.

WILLIAMS, R. Television: Technology and Cultural Form. Londres: Fontana, 1975.

Recebido : $16 / 10 / 2014$

Received: 10/16/2014

Aprovado: $11 / 11 / 2014$

Approved: $11 / 11 / 2014$ 